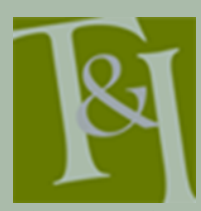

The International Journal for Translation \& Interpreting Research trans-int.org

\title{
Cognitive spaces: Expanding participation framework by looking at signed language interpreters' discourse and conceptual blending
}

\author{
Julie A. White \\ Indiana University - Purdue University at Indianapolis (IUPUI), USA \\ jaarmstr@iupui.edu
}

DOI: ti.106201.2014.a08

\begin{abstract}
We know from previous research (Metzger, 1999; Roy, 2000; Wadenjso, 1998) that interpreters are active participants within the interpreting event. We know that interpreters interact with the participants, and discourse by negotiating turn-taking, and adjusting the interpretation to meet cultural expectations. According to participation framework, speakers align themselves with the different participants in the communication event, or shift between different types of footing (Goffman, 1981). This framework has also been used to analyze interpreters, (Metzger, 1999; Roy, 2000; Wadensjo, 1982, 1998) to show how interpreters are not neutral participants in the event, but are interacting with many of the demands of the job, one of which is the discourse. In this research, which was an investigation of a monologue-interpreted event, the interpreters align themselves or blend the mental space of the original message with their interpreted message. In other words, the interpreters hold, at the minimum, two frames of footing active, simultaneously, instead of switching between the frames of footing. Cognitive linguistics, more specifically, the conceptual blending theory of Fauconnier and Turner (1996) can help expand the discussion of footing by using the theory of mental spaces (Fauconnier, 1985, 1997; Fauconnier \& Turner, 1998). The data come from the discourse of six signed language interpreters who simultaneously interpret a lecture from English to American Sign Language (ASL). The discourse of the six interpreters supports the notion that interpreters blend a space, Narrator Space, with the author of the message. In addition to this space, interpreters also use a newly identified space, Interpreter Space. Interpreter Space is a mental space where the interpreters demonstrate their processes of their interpretations through a variety of linguistic features such as producing constructed action and dialogue in ASL when it was not present in English. In addition to these spaces being identified in the data, all six interpreters seamlessly negotiated and blended several different mental spaces by using the same types of linguistic features that Deaf signers use (i.e. eye gaze, blinking, head tilting/shifting, and body shifting) (Dudis, 1997; Thumann, 2010). This study proposes the notion of using the conceptual blending process to expand the framework of analyzing and teaching interpreting.
\end{abstract}

Keywords: [conceptual blending, depiction, constructed action, constructed dialogue, mental spaces, participation framework] 


\section{Introduction}

This research study is a result of my continued interest in how American Sign Language (ASL) interpreters use constructed action (CA) and constructed dialogue (CD) when interpreting from English into ASL. Using a theory that is rooted in cognitive linguistics, the conceptual blending theory (Fauconnier \& Turner, 1998), CA/CD can be defined as a type of depiction that occurs in a mental space labeled Event Space (Dudis, 2007).

In my previous study, I had found that interpreters who had Deaf parents and identified ASL as their native language produced more instances of CA/CD in their interpretations than interpreters who learned ASL later in life (White Armstrong, 2003). The current study began with questions surrounding how native users and second language users of ASL incorporate $\mathrm{CA} / \mathrm{CD}$ into their interpretations through the lens of conceptual blending. My findings are somewhat different from my first study with additional information about blending from the framework of conceptual blending.

My initial questions for this research were about finding the possible triggers for the productions of constructed dialogue and constructed action in interpretations into ASL. Additionally I wanted to analyze the similarities and differences between native users and second language users. But, when examining my data, transcribing and coding, I began to look how CA/CD is manifested in ASL interpretations, rather than what triggers it. From this analysis, new questions began to emerge:

1) What is the process of CA/CD in ASL interpretations? Is it the same process as Deaf signers?

2) Is the conceptual blending process different? If so, how?

3) Do interpreters manipulate the same Spaces that are used in ASL constructions produced by Deaf individuals?

4) Is there a difference between the native users and second language users with their productions of CA/CD? And finally,

5) Do interpreters use CA/CD when it is not in the source language?

Constructed action is when an interpreter depicts actions of a scene as if she or some other entity is part of that scene (Metzger, 1995; Winston, 1991, 1992). Comedians are great examples of how CA is used in American English. They are known to depict the actions of others, including inanimate objects and animals. Constructed dialogue, which was originally referred to as reported speech, (Tannen, 1986) is someone incorporates the language of the people being depicted into their own discourse. The conversation(s) can include two or more different people including one's self, inanimate objects, and animals (Metzger, 1995; Roy, 1989; Tannen, 1986).

Constructed action and dialogue are used in spoken languages but are not a part of the grammatical structure or required element of the languages. Constructed action and dialogue were once thought of as an added layer to ASL and not a required or grammatical feature of ASL. They were referred to as discourse strategies that were added to make the language more interesting, more colorful, and more appealing to the audience (Mather, 1999; Roy, 1989; Winston, 2001). However, more recently, CA/CD are described as events of depiction and are required, grammatical components of ASL (Dudis, 2007; Quinto-Pozos, 2007).

Conceptual blending and the notion of mental spaces are rooted in cognitive linguistics. Blending is an idea that theorizes that we can think of concepts - actually, many at a time - and blend them with other concepts (Fauconnier, 1985, 1997; Fauconnier \& Turner, 1998). 
One mental space that is ubiquitous in ASL is Real Space, which is a conceptualization of the "here-and-now of the immediate environment based on sensory input" (Liddell, 2003, p. 367). It is a mental space that differs from other mental spaces because it is grounded in a real, physical space. Anyone watching a signer conceptualizes the person signing as well as the signer's surrounding space including objects and entities placed within that space (Liddell, 2003). For example, a signer may sign something about her sister and then position a conceptualized location of her sister, with the use of an indexed non-first person pronoun, in the space to the signer's right. By positioning her sister within the immediate proximal space in front of her and to the right, the Real Space, a blend is created by mapping the conceptualization of the signer's sister onto this space to the immediate front and right of the signer.

For example, if I want to describe (in spoken English) the location of my house ${ }^{1}$, I might utilize a table, coffee cup, and sugar bowl to describe the location and whereabouts of my house and my neighbor's house. I could use the table as the property or the land and set a coffee cup on the table to represent my house. Now you are able to blend the concept of the table with the idea of my property and the concept of the coffee cup and my house. I could then use the sugar bowl and set it proportionally on the table as my neighbor's house and then add a knife in front of the bowl and cup to represent the street, Whittier Drive. The audience would easily blend the items on the table with my house and understand the following sentence: The neighbor's house is located directly to the left side of my house.

Constructed dialogue and constructed action are the original terms for linguistic features, which appear in all languages that are currently described as depiction in the more recent literature on ASL. Depiction is the newer term that encompasses both constructed dialogue and constructed action in ASL (Dudis, 2007). Constructed dialogue and action occur in Event Space (Dudis, 1997). When a signer creates an event that includes dialogue with other individuals, a new mental space is activated. This mental space conceptualizes the event where the dialogue or action is taking place. Constructed dialogue is a way in which both the signer and the audience are able to imagine the individuals involved in the depiction of the dialogue (Dudis, 2007). For example, if a signer were to tell a story that included an incident that occurred earlier in the day and included a dialogue that happened between her professor and a friend, the story would be conceptualized in this Event Space where the incident took place.

Eye gaze has been identified to be an important determining element for when CA/CD occur. Dudis (2007) stated that when a signer creates CD, the eye gaze of the signer is no longer at the audience. The signer needs to establish a relationship with the individual conceptualized in the Event Space, and one way to do this is to change the eye gaze (and sometimes the body orientation) away from the audience and toward a conceptualized space where the "event" can occur near the signer (Dudis, 2007).

Certain features of ASL in addition to eye gaze are crucial when indicating constructed dialogue and constructed action. These features include facial expression, and body orientation (Bahan \& Supalla, 1995; Dudis, 2007; Padden, 1986; Roy, 1989; Thumann, 2010; Winston, 1991). Once a relationship is established, the conceptualized individual remains active by holding the eye gaze on that individual. More specifically, the eye

${ }^{1}$ The example, while paraphrased, is taken from Liddell, 2003. 
gaze of the signer "is continually directed towards the individual [in the constructed dialogue] even during the production of signs" (Dudis, 2007, p. $5)$.

It seems that there are minimum requirements of eye gaze and the face to be directed towards the conceptualized individual within the Event Space for the constructed dialogue to occur (Dudis, 2007). The linguistic characteristics that define this space are the changes in head position, eye gaze, facial expressions, and sometimes body orientation. These features occur just prior to or at the beginning of constructed dialogue and constructed action (Thumann, 2010).

Event Space is active when simultaneous changes occur with the linguistic features of eye gaze, facial behavior, body orientation, and the actions or signing of the person that the interpreter has become are produced (Dudis, 2007; Thumann, 2010).

The example below is taken from my study and I use vertical brackets, following Liddell (2003) to identify the concept, person, or entity being depicted. The simultaneous changes occurring here are that the interpreter's eye gaze is not at the Deaf audience; her eye gaze is at conceptualized space where |Charles| is located during this event and from the perspective of small |children| looking up at an adult. The interpreter's facial expression registers the fear the |children| must have felt.

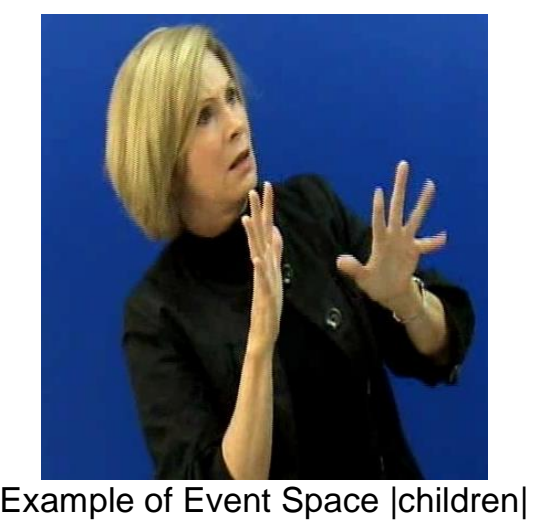

Participation framework (Goffman, 1981) has influenced the understanding of how interpreters are participants of any setting in which they work. I have used this framework and the work of Wadensjo (1992, 1998), Metzger (1999) and Roy (2000) to expand the notion of how interpreters interact with the narrator, the originator of the discourse, and the process of interpreting.

The notion of Narrator Space, which will be discussed in greater detail in the Results and Discussion section, is taken from this framework and expands the idea on how the interpreter takes on the three roles that a speaker can assume: animator, author, and principal. The role of author is described as the originator of the content and format of the utterance (Goffman, 1981). Narrator Space uses the idea that an interpreter takes on the role of author but expands this role to a blended role between the originator of the talk and the interpreter.

Wadensjo (1998) discussed how interpreters relate as narrators of others' speech. Interpreters attempt to represent the impressions of self as someone representing others' words. In other words, interpreters attempt to sound like/look like they are the narrator. Metzger (1999) stated that when an interpreter relays the message of what another person has said, she is 
understood to be the secondary author and animator while the original speaker is viewed as the primary author.

However, interpreters do much more than just relay information between parties. The additional information that interpreters relay, including the linguistic discourse decisions within their interpretations supports the notion of Interpreter Space, which will be discussed in greater detail later on in the Results and Discussion section.

Metzger (1999) also discussed in her research that interpreters generated self-utterances and were the original author of those types of utterances. With some of the self-generated utterances, the interpreter did not identify that she was the author of those utterances, which indicates a shared or blended role of narrator.

\section{Methodology}

I analyzed the interpretations of six interpreters interpreting a prerecorded 30-minute lecture in English. The same Deaf audience member sat in on every video recording. Once the participants agreed to the study, I organized the video recording in a language lab by having each interpreter come in separately at different times. Each interpreter was digitally recorded, and the interpretations were saved on a DVD. The interpretations were transcribed and annotated by me. As I analyzed the data, patterns began to emerge that indicated that the interpreters were blending mental spaces in nearly the same exact places within the discourse. There were also patterns that indicated they were using the same ASL features to negotiate the blends.

The English stimulus came from a prerecorded lecture given by Steven M. Nolt, a native English speaker and Associate Professor of History at Goshen College. At the time of the recording, he had been presenting to the general public as a response to the overwhelming interest of a book he coauthored. This book was written on the traumatic event that occurred within the Amish community in October of 2006 where a non-Amish individual took Amish children hostage and killed six girls, wounded several others, and then killed himself. I had attended one of the public lectures and decided that this text would align with the goals of my study.

One of the reasons I chose this text was that Dr. Nolt did not use an over abundance of $\mathrm{CA} / \mathrm{CD}$ in his talk that I attended. There were a few examples of $\mathrm{CD}$ within the text (which I will discuss further in the results section). One of the questions for my study was to see if the interpreters used $\mathrm{CA} / \mathrm{CD}$ when it was not in the English.

I am identifying this text as a lecture for several reasons. The discourse was a monologue from a platform with "long stretches of words coming together from a single speaker" (Goffman, 1981, p.137) with no expectation of any interaction from the audience. This lecture is very similar to the types of texts that interpreters interpret in post-secondary classrooms and conferences.

During each of the videotaped sessions of the six interpreters, a Deaf individual served as an audience member. She sat approximately 10 feet from the interpreter and next to the recording camera. Having the Deaf person sit close to the camera ensured the necessary eye contact between the interpreters and the Deaf person. The Deaf audience member did not participate in the lecture, did not ask questions, answer questions, or have 
any dialogue about the lecture. However, typical back-channeling signals did occur, such as eye gaze directed at the interpreter and head-nodding.

I wanted to investigate the work of experienced interpreters, rather than novice or newly trained interpreters, in order to analyze the practices of successful, fluent, working interpreters. (Roy, 2000) As a long-time resident in the area where I currently live, I am acquainted with many interpreters and am familiar with their professional experience. I used the following criteria to recruit the interpreters: 1) actively working as an interpreter; 2) certified by a national interpreter credentialing association; and 3) a minimum of three years of professional interpreting experience.

The average years of experience of the six interpreters was 15 years. All of the interpreters are Caucasian, are females, and vary in age from 30 to 60. These characteristics are also similar to the majority of working interpreters. As of January 2011, the national membership association in the US, the Registry of Interpreters for the Deaf (RID) reported 9083 holding national certification, $87 \%$ are Caucasian and female. Therefore, the women in this study represent a sample of the majority of signed language interpreters in the US.

Attention was given to the color clothing worn by the interpreters; all of them work solid black shirts and stood in front of a blue background. The contrast in colors facilitates visual ease when reading and analyzing signed languages.

I watched the entire interpreted versions and then identified the instances of the conceptual blending process. Those instances of conceptual blending were coded and then analyzed. I transcribed on paper the relevant linguistic units that identified the spaces. Thumann (2010) found four features, head position, eye gaze, facial expression, and body or torso position, as being significant features associated with depiction in ASL (Fridman-Mintz \& Liddell, 1998; Janzen, 2004; Liddell, 1998; Metzger, 1995; Padden, 1986; Poulin \& Miller, 1995; Roy, 1989; Swabey, 2002; Van Hoek, 1992, 1996; Winston, 1991, 1992).

The linguistic units that I identified to analyze the conceptual blending instances were: eye gaze, facial expression, and the signed vocabulary. The following is an example with the transcription/annotation conventions that I used. While only transcribing these three categories does not begin to include all of the linguistic features that occur in ASL, they were enough to identify the instances of conceptual blending.

\begin{tabular}{|c|c|c|c|c|c|c|}
\hline $\begin{array}{c}\text { Mental } \\
\text { Space }\end{array}$ & Narrator & Event & Narrator & Event & Interpreter & $\begin{array}{c}\text { Interpreter } \\
\text { /Event }\end{array}$ \\
\hline Eye Gaze & Aud & Down ctr & Aud & Left down & Aud & $\begin{array}{c}------- \\
\text { Ift dwn }\end{array}$ \\
\hline $\begin{array}{c}\text { Face } \\
\text { Behavior }\end{array}$ & Neutral & $\begin{array}{c}\text { Brows } \\
\text { furrowed - } \\
\text { Teeth } \\
\text { clenched }\end{array}$ & Neutral & $\begin{array}{c}\text { Brows } \\
\text { furrowed } \\
\text { Mouth } \\
\text { open }\end{array}$ & ------- & $\begin{array}{c}\text { Neutral } \\
-------\end{array}$ \\
\hline Gloss & PLUS & $\begin{array}{c}\text { CL: gun at } \\
\text { sides of } \\
\text { body }\end{array}$ & $\begin{array}{c}\text { Gesture: } \\
\text { 5hs: } \\
\text { "ooo" }\end{array}$ & ORDER & $\begin{array}{c}\text { CL: 2hs } \\
\text { lay on } \\
\text { floor }\end{array}$ & $\begin{array}{c}\text { Pro1 } \\
\text { SAY }\end{array}$ \\
\hline
\end{tabular}

English text: "...and he was heavily armed. He ordered everyone to lie on the floor and suggested...." [Note: The pronoun he in this example refers to Charles.] 
Transcription and annotation key

Columns: Each column indicates a new sign. Each succeeding row indicates additional linguistic information simultaneously occurring with each sign. If an annotation, -------- is used, it is used to show continuation and indicates no change.

Mental Space: This row describes which mental space is dominant. While there may be several spaces blending, the mental space listed in the transcription table is the one that is most evident.

Eye Gaze: This row describes where the eye gaze is directed. If the interpreter's eye gaze was directed at the audience, Aud is the annotation used or if the eye gaze was directed down and toward the center, down ctr is used. Other annotations include left, right, up, or down using the abbreviations $l f t, r t$, up, or down.

Face Behavior: This row describes the eyebrows and mouth (why only these two?). Additional annotative notes were used to describe these two features. For example, the eyebrows might be described as furrowed, and the mouth might be described as open or teeth clenched. The expression might be described as neutral if it is not clearly angry, happy, or sad which would typically indicate a type of depicted individual in Event Space.

Gloss: This row uses English words to describe the signs. Some transcription conventions include Prol for first person pronoun and $C L$ for classifier (a type of handshape that depicts a verb) (Liddell, 2003 ) with a description of the movement and location of the classifier.

\section{Findings and Discussion}

The analysis shows that signed language interpreters with years of experience and fluency in ASL produce CA/CD much like Deaf signers. They make use of the same types of Space, such as Real Space and Event Space, as do Deaf signers. All six interpreters marked the shift of CA/CD with changes in eye gaze, facial expression and sometimes a body and head orientation change. These changes are analogous to the changes made by Deaf signers.

In addition to this, the interpreters blend Narrator Space with the original narrator of the message. The interpreters produce instances of CA/CD when it is not in the English discourse and I call this mental space, Interpreter Space. All six interpreters, three were native users and three were second language users of ASL, performed nearly the same in every aspect. In other words, there were no significant differences between the two groups in how they produced $\mathrm{CA} / \mathrm{CD}$ and when they incorporated $\mathrm{CA} / \mathrm{CD}$ into the interpretations when it was not in the English. Forty-two instances of $\mathrm{CA} / \mathrm{CD}$ were produced at the same locations in the discourse.

The linguistic characteristics that indicate a Narrator Space that is blended with the author of the message and the interpreter:

1) The interpreter's eye gaze is towards the audience member

2) The interpreter has not created CA/CD

3) The interpreter signs first person pronouns

4) Head and body orientation are at the audience, and 
5) Pausing in different locations in the discourse than the original narrator. These pauses are marked with a change in head and body orientation, and eye gaze not at the audience, a hand clasp, and an interruption of signing.

The pauses indicate where Narrator Space is paused. The following examples are of when Narrator Space is paused; the interpreters have shifted either their body and/or head orientation and eye gaze away from the audience, signing was interrupted and a hand clasp is produced.
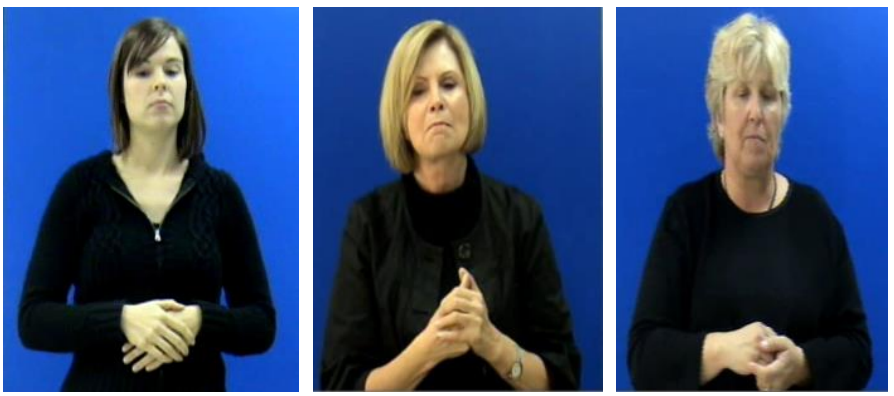

Pauses

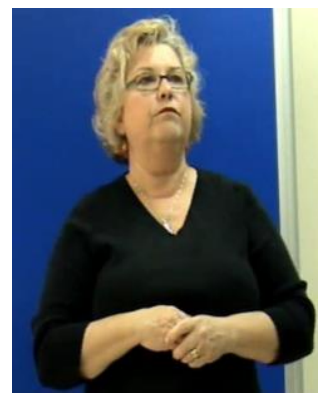

The pausing is a specific type of pausing that seems to happen during sections of the discourse where the interpreters are processing. There are other types of pausing noticeable in the interpretations, however the only type of pause that I am referring to with this study is what I call a hand clasp pause. The other types of pausing include holding a sign, nodding the head along with changes in eye behavior. There are 431 instances of the hand clasp pause with all six interpreters. These pauses occur with every interpreter in a variety of places within the interpretations.

In addition to the hand clasp pause to indicate an interruption of Narrator Space, the use of first person pronouns supports another argument for the blending of Narrator Space.

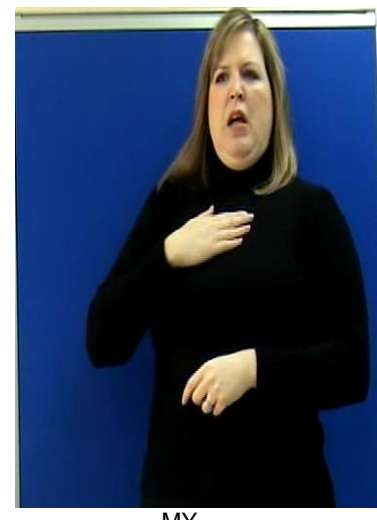

MY

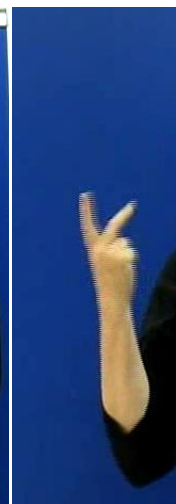

TWO-OF-US Pronouns

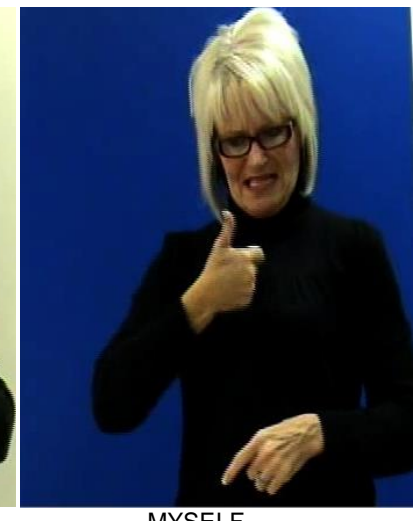

MYSELF

Even though the interpreters are using first person pronouns, they are not the original narrators of the message. They are blending Narrator Space with the original narrator. They are blending the concept of using first person pronouns with the original author. In other words, Deaf people are able to have one mental space for the original narrator of the message, another mental space of the interpreter and blend the two mental spaces together. Using first person pronouns may be a way to align the interpreters with another participant in the communicative event. 
Narrator Space through the frame of conceptual blending is one of the mental spaces that blends nearly the entire time an interpreter is interpreting. I argue this space is blended with the original narrator because 1) interpreters use personal pronouns as if they are the narrator, 2) as an interpreter begins interpreting, she "takes on" or depicts the characteristics, specifically the linguistic characteristics of the author - the narrator- of the message.

However, she does not completely and entirely depict the author; Narrator Space is a mental space blend of the author of the message and the author of the interpretation. As Wadensjo (1998) explained, interpreters are the secondary author with the primary author being the originator of the message. In Metzger's (1991) study using participation framework, she stated that there are specific utterances initiated by the interpreter that seem to function as part of the interpreting process.

This seems to support the notion of blending the Narrator Space with the original narrator; the interpreter is not entirely and completely the narrator or the original author of the message. While the interpreter is interpreting what the narrator is saying, she is also generating utterances different from what is said by the author. Therefore, the interpreter does identify as the sole narrator of the discourse. These utterances initiated by the interpreter seem to help "fulfill the goal of relaying the information" ( $p$. 100).

Wadensjo (1992) also found that interpreters do not simply function as "translation machines"; they negotiate footing shifts as they understand and relay the message (p. 72). These roles remain with the original author and are different when an interpreter gives her rendition of what the original author is saying. Interpreters take on part of the role of the author of the original message. In other words, interpreters divide the role of the narrator between themselves and the original narrator. They do not completely depict the entirety of the narrator, but blend their role as the interpreter with the role of the narrator.

Interpreter Space is the mental space that indicates the processes of interpreting. The linguistic characteristics shared by the six interpreters that reveal this space are the following:

1) The interpreters create $\mathrm{CA} / \mathrm{CD}$ when it is not in the English stimulus.

2) Interpreters shift eye gaze from the depicted event during $C A / C D$ towards the audience; this shift in eye gaze indicates a partitioning with Narrator Space and/or Interpreter Space (more analysis is needed to determine if this eye gaze is that of the Narrator Space of Interpreter Space).

3) Interpreters pause differently than the original author - they pause at different places in the discourse than the author pauses and they consistently pause with the same characteristics of a shift in body and head orientation and eye gaze away from the audience, an interruption of signing, and a hand clasp.

All six interpreters created CA/CD in the same exact locations in the discourse when it was not in the English stimulus. The data that support the claim of these identified spaces come from six interpreters interpreting a 35minute message. Within the 210 minutes of interpreted text, 42 instances of Event Space were chosen for the data analysis. At least half the interpreters created $\mathrm{CA} / \mathrm{CD}$ in these 42 instances. In addition to the 42 instances, $\mathrm{CA} / \mathrm{CD}$ were created by all of the interpreters at various times, which seems to indicate that it is not idiosyncratic behavior, but rather consistently done by 
all of the interpreters. All six interpreters created CA/CD in Event Space in much the same way as Deaf signers do.

The following examples are of an interpreter creating CA/CD. The first picture shows that the interpreter has become |Charles| and is telling the |children| to get down on the |floor|. |Charles'| eye gaze is directed at the |children| in the |schoolhouse|. The following picture is of |Charles| still directing the |children| to get on the floor, but the interpreter has shifted her eye gaze from the |children| to the audience. This is a blend of Interpreter Space (a creation of CA/CD when it was not in the English), Event Space, as she is creating CA/CD, and Narrator Space (or Interpreter Space), which can be seen through the partitioning of her face, specifically the shift in eye gaze.

Dudis (2007) states that eye gaze must remain in the depicted event $(\mathrm{CA} / \mathrm{CD})$ until the depiction is complete. However all six of the interpreters during the creations of $\mathrm{CA} / \mathrm{CD}$ shifted their eye gaze back to the audience during the depicted event, not after the depiction was complete.
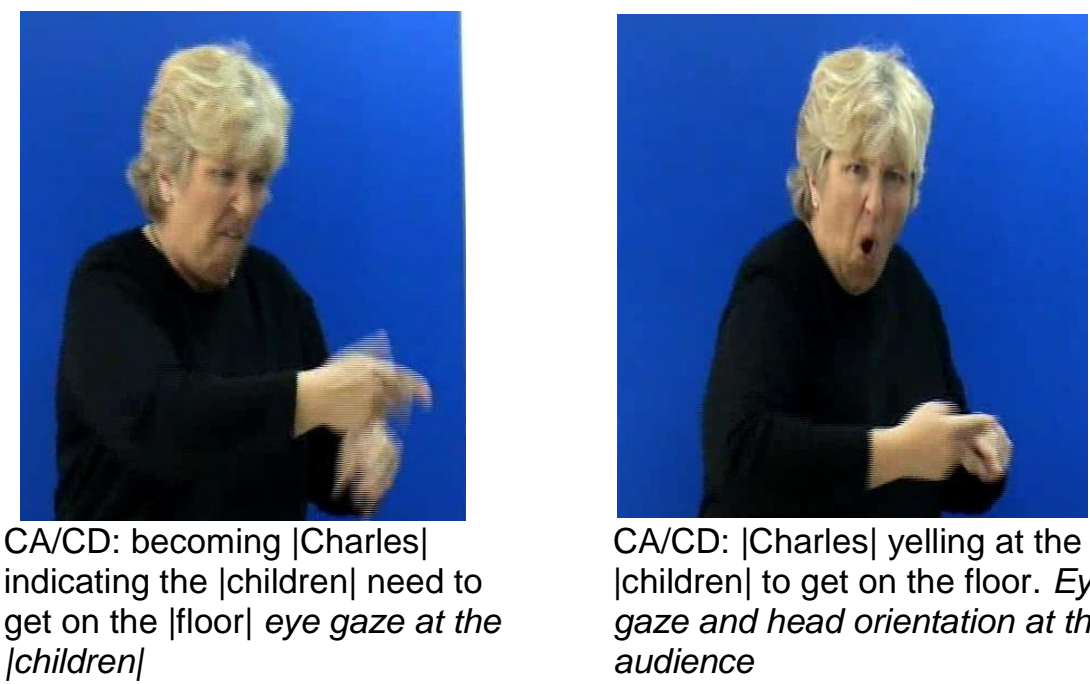

CA/CD: |Charles| yelling at the |children| to get on the floor. Eye gaze and head orientation at the audience

The following example is another example of the changes in eye gaze during a depicted event supporting the notion that several mental spaces are blending. Interpreter Space is the mental space that allows for the interpreting process to happen. And in this example, the interpreter has created CA/CD when it was not in the English stimulus. Narrator Space is blended with the originator of the message.

However, we can see the partitioning of the Narrator Space (or Interpreter Space) with the shift of eye gaze from the depicted event to the audience. The remainder of the face remains in CA/CD or Event Space, while the eyes shift or partition with the face and show two blends at once: Event Space and Narrator Space. Interpreter Space is also blended as the interpreter is using a $\mathrm{CA} / \mathrm{CD}$ when at is not in the English stimulus. 


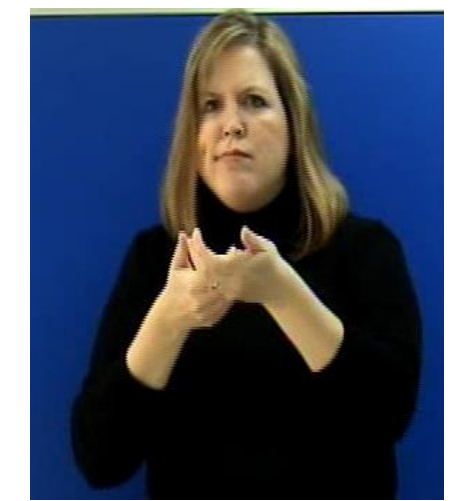

$\mathrm{CA} / \mathrm{CD}$ eye gaze at the audience |police| holding a |gun|

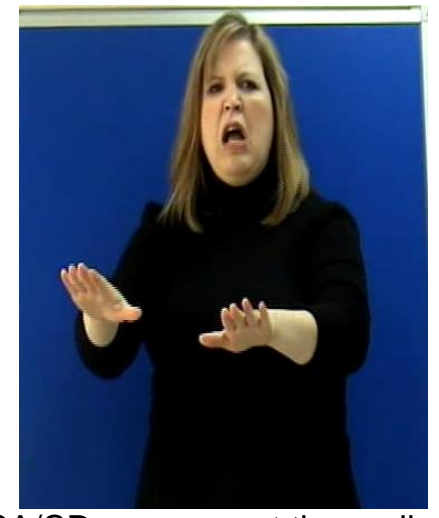

$\mathrm{CA} / \mathrm{CD}$ eye gaze at the audience |Charles| telling the |children| to get down on the |floor|

Another argument of Interpreter Space is that all six interpreters paused to process their interpretations. Through a think-aloud protocol (Lewis, 1982) interview, all interpreters shared that during the hand clap pauses, they were processing on how to interpret the next chunk of discourse. The interpreters also commented that they did not want to have the Deaf person have their attention during these pauses; these pauses are visual cues that the interpreters are not interpreting and are not visually engaged with the audience.
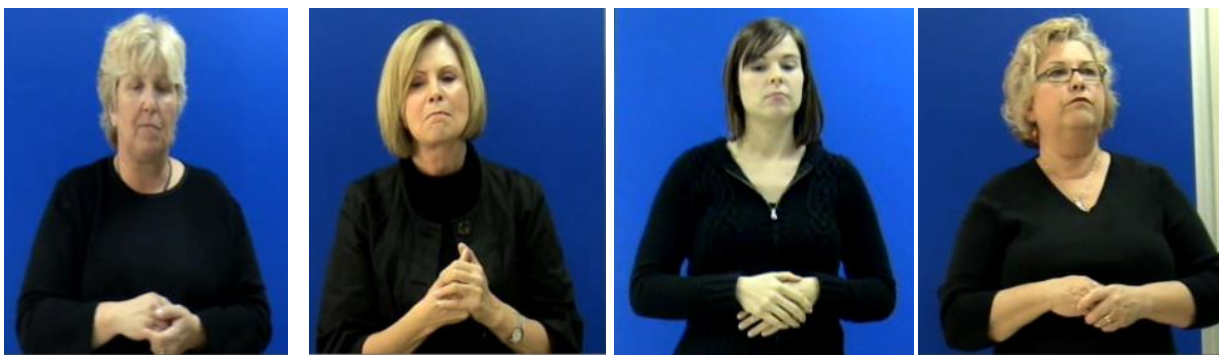

Pauses

Throughout this analysis, I have used participation framework to expand the notion of how interpreters are participants in the interpreting event. Conceptual blending and mental spaces have given us a different framework that seems to work well with the modality of signed languages. The role shifts of CA/CD both in production and comprehension along with many of the ASL features incorporated within depiction have been identified as being problematic for second language learners of ASL (Quinto-Pozos, 2005; Taylor, 2002).

However, this study shows that the second language learners of ASL performed and produced CA/CD similarly and in the same locations in the discourse as the native users. All six interpreters produced these features analogously to Deaf signers as well. Four of the interpreters had no formal education in the field of interpreting. At some point in the language acquisition of the second language users, they were able to acquire the sophisticated ASL skills needed to produce CA/CD.

This study also shows that the framework of conceptual blending can be used to analyze the mental spaces used by interpreters. This study also indicates that interpreters are able to use strategies such as a hand clasp pause and a change in eye gaze to engage or disengage the audience for 
different purposes. These strategies are sophisticated components of their overall interpretations and blend in as cohesive elements of their discourse.

As stated in earlier research, eye gaze during CA/CD has been described to remain at the depicted individual or event until the event has ended. In other words, the eye gaze has been reported (Dudis, 2007) that it does not shift back to the audience during CA/CD. Nevertheless, all six interpreters shifted eye gaze during each of the 42 analyzed productions of $\mathrm{CA} / \mathrm{CD}$. It is possible that the eye gaze shift during the productions of $\mathrm{CA} / \mathrm{CD}$ might be a way for both the interpreter and narrator (a blend of Interpreter Space and Narrator Space) to check in with the audience to see if the interpretation is clear (Interpreter Space) and see if the audience is still engaged (Narrator Space).

The 42 instances of $\mathrm{CA} / \mathrm{CD}$ in the same locations in the discourse suggest that there is a trigger for the interpreters to create this feature of ASL. The patterns of these instances of CA/CD suggest that some element(s) in the English source is triggering these productions.

Hand clasp pausing was produced similarly among all six interpreters with a change in head and body orientation and eye gaze, a cessation of signing and a hand clasp. Interpreters seem to mark this type of pause with their audience to indicate that they are, at that moment, not engaged with the audience. Interpreters reported that these pauses were a time of processing.

Could hand clasp pausing be taught to student or novice interpreters as a strategy to help with the cognitive processing of interpreting? Could it be a strategy for repair? While there are unanswered questions regarding my study, I do believe that the framework of conceptual blending has answered some questions about how interpreters use mental spaces and blending. This theory could be a beneficial theory in analyzing interpreting and useful in interpreting pedagogy. 


\section{References}

Dudis, P. (2007). Types of Depiction in ASL. Downloaded from http://drl.Gallaudet.edu.

Fauconnier, G. (1994). Mental spaces: aspects of meaning construction in natural language. Cambridge: Cambridge University Press.

Fauconnier, G. (1997). Mappings in thought and language. Cambridge: Cambridge University Press.

Fauconnier, G., \&Turner, M. (1998). Conceptual integration networks. Cognitive Science, 22 (2), 133-187.

Goffman, E. (1981). Forms of Talk, Philadelphia: University of Pennsylvania Press.

Janzen, T. (2004). Space rotation, perspective shift, and verb morphology in ASL. Cognitive Linguistics 15 (2): 271-306.

Liddell, S. (1995). Real, surrogate, and token space: Grammatical consequences in ASL. In K. Emmorey \& J. Reilly (Eds.), Language, gesture, and space (pp. 19-41). Hillsdale, NJ: Lawrence Erlbaum Associates.

Liddell, S. (1998). Grounded blends, gestures, and conceptual shifts. Cognitive Linguistics, 9(3), pp. 283-314.

Liddell, S. (2003). Grammar, gesture, and meaning in American Sign Language. Cambridge: Cambridge University Press.

Metzger, M. (1995). Constructed dialogue and constructed action in American Sign Language. In C. Lucas (Ed.), Sociolinguistics in Deaf communities (pp. 255 - 271). Washington, D.C.: Gallaudet University Press.

Padden, C. (1986). Verbs and role-shifting in American Sign Language. In C. Padden (Ed.), Proceedings of the fourth national symposium on sign language research and teaching, Las Vegas, Nevada ( pp. 44-57). Published by the National Association of the Deaf.

Quinto-Pozos, D. (2005). Factors that influence the Acquisition of ASL for interpreting students. In M. Marschark, R. Peterson, \& E. Winston (Eds.), Sign language interpreting and interpreter education: Directions for research and practice ( pp. 159-187). New York: Oxford University Press.

Quinto-Pozos, D. (2007). Can constructed action be considered obligatory? Lingua, 117, 1285-1314.

Roy, C. (1989). Features of discourse in an American Sign Language Lecture. In C. Lucas (Ed.), The sociolinguistics of the Deaf community (pp. 231-251). New York: Academic Press, Inc.

Roy, C. (2000). Interpreting as a discourse practice. New York, New York: Oxford University Press.

Registry for Interpreters of the Deaf. (2011). RID Views 28(1). Alexandria, VA: RID Press. Retrieved from RID website: http://www.rid.org/publications/views/index.cfm/AID/109

Tannen, D. (1986). Introducing constructed dialogue in Greek and American conversational and literary narratives. In F. Coulmas (Ed.), Direct and indirect speech (pp. 311-332). Berlin: Mouton

Tannen, D. (1989). Talking voices: Repetition, dialogue, and imagery in conversational discourse. Cambridge: Cambridge University Press.

Taylor, M. (2002). Interpretation skills: American Sign Language to English. Edmonton, Alberta: Interpreting Consolidated. 
Thumann, M. (2010). Identifying depiction in ASL presentations. (Doctoral dissertation). Retrieved from http://www.sendspace.com/file/dis12k

White Armstrong, J. (2003) An investigation of constructed action and dialogue in American Sign Language interpreted lecture. Unpublished master thesis. Ball State University, Muncie, IN.

Winston, E. (1991). Spatial referencing and cohesion in an American Sign Language text. Sign Language Studies, 73, 397-409.

Winston, E. (1992). Space and involvement in an American Sign Lecture. In J. Plant- Moeller (Ed.), Expanding horizons: Proceeding of the Twelfth National Convention of the Registry of Interpreters for the Deaf (pp. 93-105). Silver Spring, MD: Registry of Interpreters for the Deaf. 